\title{
Acute angle closure glaucoma: relative failure of YAG iridotomy in affected eyes and factors influencing outcome
}

\author{
S A Buckley, B Reeves, M Burdon, C Moorman, S Wheatcroft, C Edelsten, L Benjamin
}

\begin{abstract}
The treatment of acute angle closure glaucoma has been influenced by the development of the YAG laser and its ability to perform iridotomies as an outpatient procedure. In this retrospective study the results of YAG iridotomy were compared with surgical peripheral iridectomy. When compared with surgical peripheral iridectomy patients, YAG iridotomy patients were at greater risk of proceeding to further surgery, with this risk being significantly associated with increasing duration of attack. The authors suggest that in selected cases, surgical iridectomy should be given consideration as a primary procedure. (Br F Ophthalmol 1994; 78: 529-533)
\end{abstract}

Acute angle closure glaucoma (AACG) is an ophthalmic emergency, with an urgent necessity to lower intraocular pressures to minimise visual loss. Treatment involves initial lowering of the pressure using medical means such as miotics, acetazolamide, and osmotic diuretics, followed by some form of surgical intervention for a permanent solution. Surgical treatment of AACG was first introduced by von Graefe $^{1}$ in 1857 who found that broad iridectomy was an effective operation for acute glaucoma. In 1920 , Curran $^{2}$ was the first to explain the concept of pupil block in AACG and described surgical iridotomy as an alternative treatment. Chandler in 1952 developed the technique of peripheral iridectomy thus creating a large low resistance pathway for aqueous flow. With the advent of the YAG laser it is possible to create successful iris iridotomies without recourse to surgery.

Today the common interventional procedures used to relieve pupil block are either YAG laser iridotomy (YPI) or surgical peripheral iridectomy (SPI). Trabeculectomy - that is, a filtering operation, is reserved for patients who either have significant angle damage, prolonged attacks not responding to treatment, or who need a second procedure when the first one fails.

In the literature, there are conflicting reports on the importance of factors such as age, intraocular pressure (IOP), and duration of attack (DOA) ${ }^{4-7}$ Recent studies ${ }^{8}$ have indicated that there is a minimum size for the peripheral iridotomy, and with small iridotomies there may be too large a resistance to aqueous flow for sufficient relief of the pupil block. Other authors have promoted SPI rather than YPI for the treaxment of AACG especially in cases of prolonged attacks. ${ }^{910} \mathrm{By}$ collecting a large number of patients with AACG, we hoped to elucidate factors affecting outcome, as well as the success of the various treatment options used.
Four aims of the study were established:

(1) to investigate which eyes are at highest risk of a poor visual outcome;

(2) to compare effectiveness of the interventional methods used;

(3) to examine cataract formation in presenting eyes;

(4) to monitor the effectiveness of treatment in preventing recurrent AACG.

\section{Method}

Retrospective data were collected from patients who had presented with AACG to the Oxford Eye Hospital (OEH), Birmingham Eye Hospital (BEH), Royal Berkshire Hospital (RBH), and Stoke Mandeville Hospital (SMH). Patient information was obtained on a minimum of 30 consecutive patients presenting with AACG to each centre, beginning 1 year before the collecting date and working backwards. AACG can be confused with other conditions such as rubeotic and chronic angle closure glaucoma. Therefore to confirm a retrospective diagnosis of AACG, in addition to the working diagnosis made at the time, the documented symptoms and signs had to include at least four of the following: pain, sudden onset of symptoms, nausea or vomiting, conjunctival injection, blurred vision or haloes around lights, raised IOP, and shallow anterior chambers or closed angles on gonioscopy. If patients did not fulfil these criteria they were excluded from the study.

A total of 161 patients presenting between December 1986 and January 1990 were reviewed. Information collected included age, sex, presenting and best recorded visual acuity after the attack; presenting IOP, total duration of attack that is, delay in presentation plus time taken to control the acute attack and bring the IOP down to $20 \mathrm{~mm} \mathrm{Hg}$ or less, medical and surgical treatment, and development of cataract.

In order to analyse data by parametric statistical methods, best recorded visual acuity outcome (VA) Snellen acuities were converted into $\log$ MAR $^{11}$ scores using the nearest $\log$ MAR equivalent (see Table 1). Counting fingers vision (CF) was considered to be approximately equivalent to $2 / 60(1.5 \log M A R)$. Eyes described as having hand movements (HM), perception of light (PL), and no perception of light (NPL) acuities were not assigned $\log$ MAR equivalents and were excluded from all analyses in which VA was a dependent variable.

\section{Results}

There were 161 patients, 40 men and 121 women with a mean age of 68 years (range 38 to 92 years); 
Table 2 Numbers (\%) of patients undergoing procedures and their outcome

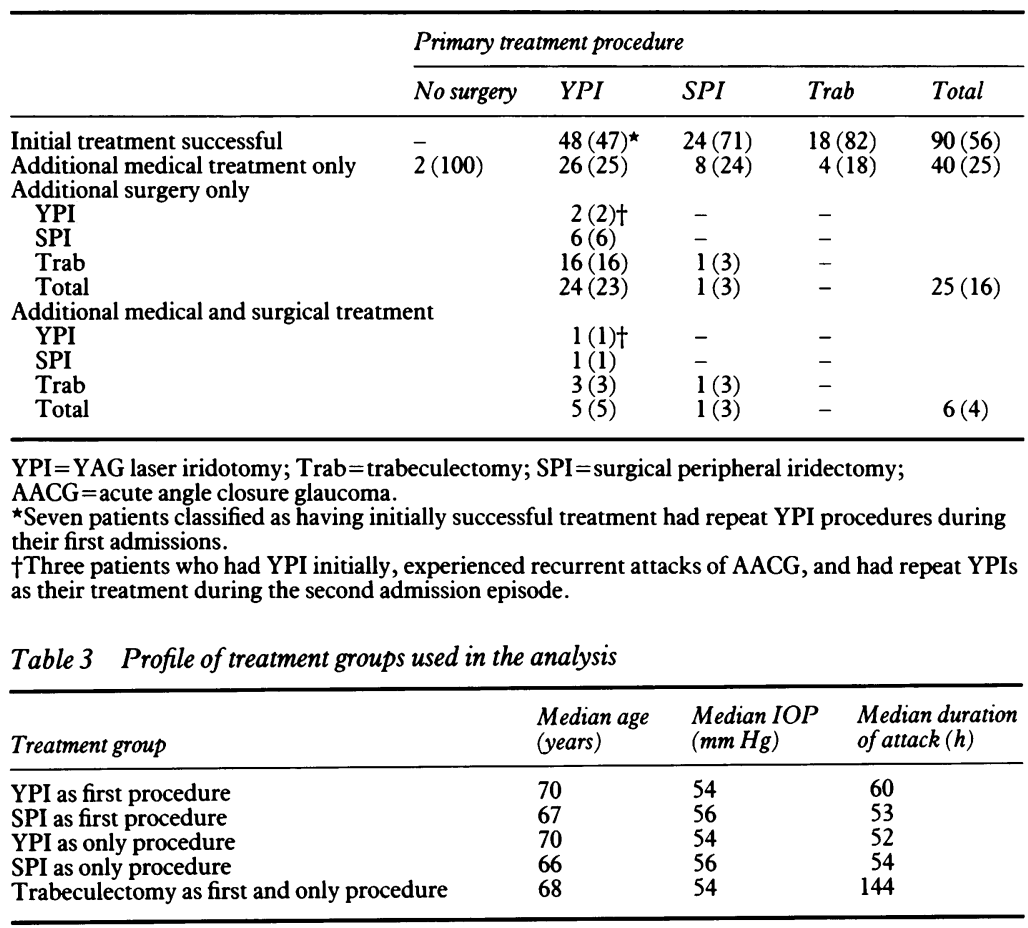

104 were GP referrals, nine were hospital inpatients, while the remainder presented via casualty departments. On presentation, all patients received standard medical treatment to relieve the acute pressure episode - that is, topical miotics and systemic osmotic agents. Measures taken to prevent future episodes of raised IOP included long term medical therapy, YPI, SPI, and trabeculectomy. Because these additional measures were sometimes unsuccessful, some patients had a combination of treatments. Table 2 summarises the treatment options patients underwent. Table 3 shows the median age, presenting IOP, and DOA for different treatment groups. The treatment groups are similar with respect to age and presenting IOP, but those patients who had trabeculectomy as the primary procedure tend to have a longer duration of attack.

\section{PREDICTORS OF FINAL VISUAL ACUITY FOR AFFECTED EYES}

The final VA was analysed with reference to the variables of age at presentation, presenting IOP, and total duration of attack. Because of the retrospective nature of the study, there were considerable missing data. Complete information about age, presenting IOP, duration of attack, and VA was available for 104 of the 161 patients reviewed. Only five patients were excluded from analysis solely on the basis of final visual acuity being HM or less. The distributions of the $\log$ MAR visual acuity scores and duration of attack (DOA) were positively skewed and were transformed logarithmically before analysis. A constant of 0.4 was added to the visual acuity scores before carrying out the logarithmic transform to avoid attempting to take the log of negative or zero logMAR scores.

Visual outcome was likely to be related to increasing age, since other studies show a natural
Table 4 Stepwise multiple regression analysis to predict visual acuity

\begin{tabular}{|c|c|c|c|c|c|}
\hline \multirow[b]{2}{*}{ Step } & \multirow{2}{*}{$\begin{array}{l}\text { Variable } \\
\text { entered }\end{array}$} & \multicolumn{2}{|c|}{ Multiple } & \multirow{2}{*}{$\begin{array}{l}\text { Change } \\
\text { in } R S Q\end{array}$} & \multirow{2}{*}{$\begin{array}{l}\mathrm{F} \text { to } \\
\text { enter }\end{array}$} \\
\hline & & $R$ & $R S Q$ & & \\
\hline$\frac{1}{2}$ & $\begin{array}{l}\text { Age } \\
\log (\mathrm{DOA})\end{array}$ & $\begin{array}{l}0.3261 \\
0.3816\end{array}$ & $\begin{array}{l}0 \cdot 1063 \\
0 \cdot 1456\end{array}$ & $\begin{array}{l}0 \cdot 1063 \\
0 \cdot 0393\end{array}$ & $\begin{array}{l}9.87 \\
3.77\end{array}$ \\
\hline
\end{tabular}

ANOVA table

\begin{tabular}{lrlll}
\hline Source & $d f$ & $M S$ & F ratio & $p$ Value \\
\hline $\begin{array}{l}\text { Regression } \\
\text { Residual }\end{array}$ & 2 & 0.2761 & 6.99 & $<0.01$ \\
\hline
\end{tabular}

Regression equation:
$\log (\mathrm{LDVA}+0 \cdot 4)=-0.7724+0.0047(\mathrm{age})+0 \cdot 1096(\log (\mathrm{DOA}))$.

deterioration in visual function with increasing age. ${ }^{12}{ }^{13}$ To try and reduce this component of any relation, it was assumed that the visual acuity of the unaffected fellow eyes represented the best estimate of a patient's visual acuity in the affected eye before the attack of AACG. Therefore, the difference in visual acuity $(\log (\mathrm{DLVA}))$ between the affected and fellow eyes was used as the standard outcome variable. Patients with known coexisting ocular pathology in both presenting and fellow eyes were excluded as were patients with bilateral attacks. Complete data were available for 85 patients.

$t$ Tests for differences between patients included and patients excluded from the analysis were carried out wherever possible. Excluded patients did not differ from included ones with respect to age, $\log (\mathrm{DLVA})$, or duration of attack. However, excluded patients had a significantly lower mean presenting IOP of 53.3 $\mathrm{mm} \mathrm{Hg}$ compared with $57.5 \mathrm{~mm} \mathrm{Hg}$ for included patients $(\mathrm{p}=0.03)$.

A stepwise multiple regression fitted sex, hospital, primary treatment procedure, age, IOP, and $\log (\mathrm{DOA})$ as predictors of $\log$ (DLVA). Age was the best predictor of $\log (\mathrm{DLVA})$, with $\log (\mathrm{DOA})$ also contributing significantly to the regression $(\mathrm{p}<0.01)$ (see Table 4$)$

\section{EFFECTIVENESS OF YAG IRIDOTOMY VERSUS} SURGICAL IRIDECTOMY

The two recognised methods of relieving pupil block by creating an alternative pathway for aqueous flow are YPI and SPI. Trabeculectomy is a conventional drainage procedure, usually reserved for patients with prolonged attacks (see Table 3). ${ }^{9}$ The groups YPI and SPI are similar in terms of age, IOP, and DOA allowing comparisons between them.

\section{Visual acuity outcome between YPI and SPI}

Analysis of variance was restricted to the 106 patients who received just one form of interventional treatment (YPI or SPI), using the covariates of age, IOP, and $\log (\mathrm{DOA})$ against the dependent variable of $\log (\mathrm{DLVA})$. Fifty eight patients (YPI $n=38$; SPI $n=20$ ) had complete data and were included in the analysis. Analysis of the data for included and excluded patients showed no difference for age, IOP, duration of attack, and $\log$ (DLVA). There was no difference between the adjusted visual acuity for YPI and 
SPI treatment groups $(F=0 \cdot 24, \mathrm{df}=1$ and 53 , $\mathrm{p}=0 \cdot 63)$.

Likelihood of requiring a second surgical procedure YPI patients who had an SPI or trabeculectomy to gain adequate IOP control, or who had repeat YPI because of recurrent attack of AACG were classified as requiring a second surgical procedure (see Table 2). Repeat YAG iridotomies for non-patency only were not considered as a second procedure. SPI patients who went on to have a subsequent trabeculectomy were also considered as having a second surgical procedure. A logistic regression analysis using sex, hospital, primary treatment procedure, age, IOP, and $\log (\mathrm{DOA})$ variables as predictors of the need for further surgical procedure was carried out. Patients who had YPI as the initial procedure had a significantly greater risk of needing a second surgical procedure, when compared with SPI patients (relative risk $8 \cdot 88$; 95\% confidence limits (CL) $1 \cdot 1-72 \cdot 1$; improvement in $\chi^{2}=$ $7 \cdot 51 ; \mathrm{df} 1 ; \mathrm{p}=0 \cdot 006)$. None of the other variables was significantly associated with the need for further surgery.

Logistic regression analysis using the same variables as predictors as to which YPI patients required further surgery showed that $\log (\mathrm{DOA})$ was the only variable for which there was any suggestion of an association with the need for further surgery. (The increase in risk for every 10 -fold increase in DOA was 3.25 ; CL 0.94 11.2 ; improvement in $\chi^{2} 3 \cdot 72, \mathrm{df}=1, \mathrm{p}=0.054$.)

Likelihood of requiring long term medical treatment Data for the 137 patients who received YPI or SPI as primary procedures were analysed (see Table 5). There was no evidence that YPI patients were more likely to require long term medical treatment (relative risk $=1.63,95 \%$ $\mathrm{CL}=0 \cdot 64-4 \cdot 13$ ). Logistic regression of the $96 /$ 137 patients with complete data showed that DOA was associated with the need for long term medical treatment; each 10-fold increase in DOA representing a risk of $3.46(\mathrm{CL}=1 \cdot 10-10 \cdot 9$; improvement in $\left.\chi^{2}=4.77, \mathrm{df}=1, \mathrm{p}=0.03\right)$. Females were less likely than males to require long term medical treatment (relative risk $=0.30$; $\mathrm{CL}=0 \cdot 12-0.78$; improvement in $\chi^{2}=6 \cdot 25$, $\mathrm{df}=1, \mathrm{p}=0.012$ ).

\section{Effect of hospitals, power used, and grade operator} on success of YPI

The four hospitals used four different makes of Q switched YAG lasers, only one of which could operate in multimode as well as fundamental mode. Analysis was undertaken to determine if using different models and modes affected the success and failure rates of YPI. Since there were more observations for $\mathrm{OEH}$ than the others, $\mathrm{OEH}$ was considered as the baseline hospital and

Table 5 Numbers (\%) of patients requiring long term medical treatment after only one procedure

\begin{tabular}{llll}
\hline Treatment group & $Y P I$ & \multicolumn{1}{c}{ SPI } & Total \\
\hline No medical treatment & $48(65)$ & $24(75)$ & $72(70)$ \\
Long term medical treatment & $26(35)$ & $8(25)$ & $34(30)$ \\
\hline
\end{tabular}

Table 6 Comparison of failure of YAG laser between the four hospitals

\begin{tabular}{lll}
\hline Hospitals & \multicolumn{2}{l}{ Results of comparisons } \\
\hline OEH $v$ SMH & Odds ratio $=1 \cdot 105$ & $\mathrm{CI}=0.411$ to 2.968 \\
OEH $v$ BEH & Odds ratio $=1 \cdot 105$ & $\mathrm{CI}=0.401$ to 3.042 \\
OEH $v$ RBH & Odds ratio $=0.491$ & $\mathrm{CI}=0.130$ to 1.859 \\
\hline
\end{tabular}

Table 7 Comparison of power used in YPI

\begin{tabular}{|c|c|c|}
\hline \multirow{2}{*}{$\begin{array}{l}\text { Power quartiles } \\
\text { Quartile } 1 v \text { quartile } 2 \\
\text { Quartile } 1 v \text { quartile } 3 \\
\text { Quartile } 1 v \text { quartile 4 }\end{array}$} & \multicolumn{2}{|l|}{ Results of comparisons } \\
\hline & $\begin{array}{l}\text { Odds ratio }=0.750 \\
\text { Odds ratio }=0.818 \\
\text { Odds ratio }=1 \cdot 768\end{array}$ & $\begin{array}{l}\mathrm{CI}=0.203 \text { to } 2.770 \\
\mathrm{CI}=0.219 \text { to } 3.055 \\
\mathrm{CI}=0.461 \text { to } 6.776\end{array}$ \\
\hline $\begin{array}{l}\text { Analysing the power a } \\
\text { Adjacent } 2 \text { quartiles }\end{array}$ & $\begin{array}{l}\text { ontinuous variable: } \\
\text { Odds ratio }=1 \cdot 202\end{array}$ & $\mathrm{CI}=0.789$ to 1.830 \\
\hline
\end{tabular}

compared with the others using odds ratios (see Table 6). The estimate for RBH was small because only a few patients had YPI as the primary procedure. This was reflected in the $\mathrm{CI}$ figures showing the estimate to be imprecise. Overall there are certainly no significant differences between hospitals.

A surprisingly wide range of powers was used from $7 \mathrm{~mJ}$ to $454 \mathrm{~mJ}$. The energies used were divided into quartiles and then compared (see Table 7). The odds ratios were not significant however analysed, so YAG failure was not related to power used.

Senior registrars were the most common operators of the YAG laser accounting for 52 of the available data (16/103 missing). Analysis of the odds ratios between the grades of operator showed no significant difference in failure rates and this was supported with a $\chi^{2}$ test across all grades $\left(\chi^{2}=4 \cdot 38, \mathrm{df} 3, \mathrm{p}>0 \cdot 2\right)$. However, using a $\chi^{2}$ trend test, there was some evidence of a trend for YAG failure to be less likely with more senior operators $\left(\chi^{2}=3 \cdot 87\right.$, df $\left.1, \mathrm{p}=0 \cdot 049\right)$. This was confirmed by a logistic regression which gave an odds ratio of $0.555(\mathrm{p}=0.054, \mathrm{CI}=0.305$ to 1.009). Therefore it would appear that a YAG laser iridotomy performed by a consultant was less likely to fail than one performed by an SHO.

RISK OF CATARACT FOLLOWING AN ATTACK OF AACG Cataract may occur following AACG either because of the AACG attack itself or as a complication of the surgical procedures used. Because many AACG patients who had YPI or SPI had the same treatment to the fellow eye, there was an opportunity to investigate these two factors more closely.

A patient was classified as having a cataract if he/she

(a) had had a cataract extraction during the period of follow up,

(b) had been placed on the waiting list for cataract extraction, or

(c) if there was clear documentation of significant cataract in the patient's clinical records.

Risk of cataract in the affected versus the fellow eye Cases with different treatments to presenting and fellow eyes, bilateral cases of AACG, cases where the AACG attack was precipitated by intumescent cataracts, and only eyes were 
Table 8 Numbers (\%) developing cataract in presenting and fellow eyes undergoing one procedure only

\begin{tabular}{lll}
\hline Development of cataract & $Y P I$ & $S P I$ \\
\hline Presenting eyes & $17 / 74(23)$ & $7 / 32(22)$ \\
Fellow eyes & $10 / 122(8)$ & $1 / 24(4)$ \\
\hline
\end{tabular}

excluded from the analysis. Data were available for 85 pairs of eyes; 69 patients had no cataract in either eye, eight had cataracts in both eyes, eight had cataract in the affected eye only, and none had cataract in the fellow eye only. These figures show that there was a significantly greater risk of cataract in the presenting eye than in the fellow eye $\left(\mathrm{McNemar}\right.$ test; $\left.\chi^{2}=6 \cdot 125, \mathrm{df}=1, \mathrm{p}<0 \cdot 02\right)$.

\section{Risk of cataract for different surgical procedures} The risk of developing cataract for the YPI and SPI groups was compared in both presenting (106) and fellow eyes (146) which had undergone only one surgical procedure (see Table 8 ). There was no evidence of a greater risk of cataract following YPI than SPI for presenting $(R R=$ $1.94,95 \% \mathrm{CL}=0.59-6.33)$ or fellow eyes $(\mathrm{RR}=2 \cdot 05,95 \% \mathrm{CL}=\mathbf{0} \cdot 25-16 \cdot 84)$. However, the small number of cataracts and overall sample size mean that the current data would be unable to demonstrate a small difference in risk.

\section{Analysis of change in visual acuity post $A A C G$ in presenting eyes with cataract}

Unfortunately, despite eliminating all cases where cataract was recognised clinically as being the precipitating factor, one cannot determine directly if the cataracts in the presenting eyes were a product or a cause of the AACG. Indirectly one can look at the rate of cataract development in presenting and fellow eyes, on the assumption that there is a relation with visual loss during follow up. There were 14 eyes in which cataract developed in the presenting eye, with 1 year of follow up data. The mean $\log M A R$ visual acuity scores were analysed and there was a moderately significant effect of duration of follow up with the difference between VA in presenting and fellow eyes becoming greater with time $(F=4 \cdot 37, \mathrm{df}=2$ and $26, \mathrm{p}=0 \cdot 02)$. That is, the visual loss after AACG was more rapid in the presenting eye than the fellow.

\section{EFFECTIVENESS IN PREVENTING AACG}

Despite undergoing YPI, a small number of patients experienced recurrent AACG attacks in their presenting eyes $(7 \%)$, or new attacks in fellow eyes (4\%) (see Table 9). In addition two of the presenting eyes had undergone previous prophylactic YAG iridotomies that had not prevented the attack of AACG. Although none of the SPI patients had a recurrent attack, the number of cases was too few to demonstrate any

Table 9 Numbers (\%) of recurrent attacks of acute angle closure glaucoma (AACG) in both presenting and fellow eyes after treatment

\begin{tabular}{lll}
\hline Further attack AACG & $Y P I$ & $S P I$ \\
\hline Presenting eyes & $7 / 103(7)$ & $0 / 34(0)$ \\
Fellow eyes & $5 / 127(4)$ & $0 / 24(0)$ \\
\hline
\end{tabular}

statistically increased risk for presenting or fellow eyes.

\section{Discussion}

Ideally, evaluation of alternative strategies for disease management should be based on randomised clinical trials. However, observational or retrospective data can provide important information if randomised trials are not practicable. ${ }^{14}$ In the present study, we are interested in comparing the primary surgical treatments of YPI and SPI for AACG. In order to recruit a similar sized sample of patients, a prospective study would have to run for several years in four centres, with associated costs and administrative difficulties. Because of this, a retrospective study is the more feasible option. Although this type of design can be criticised for being unrepresentative, subject to selection biases in treatment allocation and vulnerable to considerable missing data, we believe the design of the study and the methods of data analysis reduce the effect of these limitations.

To obtain representative data, patient records of consecutive cases of AACG at participating hospitals were examined. Additional criteria requirements for a retrospective diagnosis of acute angle closure glaucoma avoid inclusion of other causes of raised intraocular pressure, such as chronic angle closure. In three hospitals, YPI was the preferred primary treatment while SPI was usually carried out in the fourth. Therefore, given that within any hospital sample the majority of patients were allocated to the same treatment, it is unlikely that there was a significant selection bias in the allocation of patients to SPI or YPI treatments.

Analyses showed that there were no significant effects associated with particular hospitals. Although there were many missing data, there is little evidence that cases with missing data differed from those with complete data.

The best recorded visual acuity after an attack of AACG is a realistic endpoint for study. As far as we know this is the first analysis of AACG to show that both increasing age and longer duration of attack have a detrimental effect on final visual outcome. Ingram and Ennis showed that the prognosis for visual recovery decreases significantly with increasing age. ${ }^{4}$ Other retrospective studies ${ }^{45}$ looking at duration of attack showed no direct relation to visual prognosis, unlike our findings. The strong relation of final visual outcome to age may be related to reduction in optic nerve head perfusion with increasing age, ${ }^{15}$ making it more vunerable to anoxic damage from sustained rises in intraocular pressure. The longer the duration of attack the greater the risk of permanent visual damage, as shown by the regression analysis.

There are few studies comparing different treatment modalities in presenting eyes. YAG laser, because of its convenience and with no need for anaesthesia and theatre time, is now at the forefront of treatment for AACG, usually as the first line treatment. Surgical iridectomy is still performed in some centres as the primary procedure in presenting eyes, though not necessarily the fellow eyes. ${ }^{10}$ Drainage procedures are occasionally the first line treatment, usually used 
in cases of long standing or resistant AACG. ${ }^{9}$

Twenty seven per cent required long term medical treatment after all treatments. Other studies put this figure between $19 \%{ }^{16}$ and $24 \% .{ }^{17}$ There was no difference between the YPI and SPI groups regarding the numbers of patients requiring topical treatment but there was an increased risk with increasing DOA. The exact mechanism for this late rise is unknown. It could be because of persistence of peripheral anterior synechiae or trabecular meshwork damage sustained during the acute episode. To function properly in normal situations the trabecular meshwork must be compliant, so that pressure responsive structural changes can take place to allow aqueous outflow. ${ }^{18}$

Looking at further surgical procedures, patients undergoing YPI had a significantly greater risk of needing a second surgical procedure compared with those who had SPI as a primary procedure. In performing an SPI, unlike YPI, two mechanisms are postulated in the opening of the closed angle. ${ }^{9}$ Firstly, the angle is opened directly at the site of the iridectomy and, secondly, the angle is opened in other quadrants when the iris is prolapsed or pulled out of the anterior chamber to perform the iridectomy. Therefore SPI will be more successful in any patient who has persistent and more extensive closure of the drainage angle after medical treatment. In the YPI group, those patients who needed a second surgical procedure or long term medical treatment were those who had a longer attack. Similarly, David et $a l^{6}$ found that early presentation of AACG required less treatment than those who presented late. There is potentially increased angle compromise with increased length of attack.

We found no statistical difference between the number of cataracts between YPI and SPI in either the presenting or the fellow eye. Fleck ${ }^{19}$ also found no difference in cataract development between YAG iridotomy and surgical PI in fellow eyes after 1 year of follow up. In both groups of patients there were significantly more cataracts occurring in the presenting eye when compared with the fellow eye, even when cases thought to have been precipitated by cataract were excluded. Looking at the change in visual acuity after the AACG, visual acuity apparently deteriorated more rapidly in presenting eyes compared with fellows suggesting a more rapid rate of cataract formation. To our knowledge this has not been considered previously in ophthalmic literature, and the mechanisms by which AACG causes alterations in lens metabolism resulting in more rapid development of cataract are at present unknown.

YPI and SPI should prevent further AACG attacks, but AACG occurred in 14 patients following YPI. None of the patients in the SPI group had any further attacks. With YAG laser iridotomies smaller holes are being made in the iris, as happened before the introduction of peripheral iridectomy. Gifford ${ }^{20}$ observed in 1921 , that small surgical iridotomies were not as effective in controlling intraocular pressure as larger iridotomies. Gray $e t a l^{21}$ and Fleck ${ }^{8}$ described AACG occurring in the presence of a patent iridotomy. Fleck ${ }^{8}$ argued that this could be the result of the resistance across a small iridotomy being too great for free flow of aqueous to relieve the pupil block.

Although the technique of YAG laser iridotomy is theoretically simple, it can be complicated by the oedematous hazy cornea, shallow anterior chamber and thickened iris of the patient with AACG. Thirty five per cent of YPIs in our study were not successful at the torst attempt. Of these just under a third succeeded with a YPI on the second and sometimes the third attempt, but the remainder required surgical intervention. SPI has been shown to be very effective in the management of prolonged attacks of acute congestive glaucoma, ${ }^{9}$ and less likely to run the risk of malignant glaucoma than a filtering procedure. ${ }^{22}$ We have shown that both age and duration of attack have an adverse effect on visual outcome. Duration of attack is also associated with increased medical treatment and second surgical procedures in the YPI group. Therefore it would appear that if there is a delay in presentation especially in the elderly patient, surgical iridectomy should be given consideration as the first surgical option.

The analysis was discussed with John Thompson, statistician, Department of Ophthalmology, University of Leicester. Further details of the analysis are available on application to B Reeves, Nuffield Laboratory, Oxford Eye Hospital, Radcliffe Infirmary.

1 Von Graefe A. Uber die Iridectomie bei Glaucoma und uber den glaucomatosen Process. Graefes Arch Clin Exp Ophthalmol 1857; 3: 456-555.

2 Curran EJ. A new operation for glaucoma involving a new principle in the aetiology and treatment of chronic primary principle in the aetiology and treatment of ch
glaucoma. Arch Ophthalmol 1920; 49: 131-55.

3 Chandler PA. Narrow angle glaucoma. Arch Ophthalmol 1952; 47: 695-716.

4 Ingram RM, Ennis JR. Acute glaucoma: results of treatment by bilateral simultaneous iridectomy, now without admission to hospital. Brf Ophthalmol 1983; 67: 367-71.

5 Hillman JS. Acute closed angle glaucoma: an investigation into the effect of delay in treatment. Br $\mathcal{F}$ Ophthalmol 1979; 63: 817-21.

6 David R, Tessler Z, Yassur Y. Long term outcome of primary acute angle closure glaucoma. Br $\mathcal{F}$ Ophthalmol 1985; 69: 261-2.

7 Playfair TJ, Watson PG. Management of acute primary angle closure glaucoma: a long term follow up of the results of
peripheral iridectomy used as an initial procedure. $B r \mathcal{F}$ peripheral iridectomy used

8 Fleck BW. How large must an iridotomy be? Brf Ophthalmol 1990; 74: 583-8.

9 Newhouse RP, Schutz S. Sector iridectomy in the management of prolonged attacks of acute congestive glaucoma. Ann Ophthalmol 1987; 19: 340-6.

10 Koch JM, Tenger M, Goldmann D, Mellin KB, Waubke TN. Surgical iridectomy following acute angle closure glaucoma. A retrospective study of 107 patients. Fortschr Ophthalmol 1990; 87: 449-52.

11 Bailey IL, Lovie JE. New design principles for visual acuity letter charts. Am $\mathcal{F}$ Optom Physiol Opt 1976; 53: 740-5.

12 Slataper FJ. Age norms of refraction and vision. Arch Ophthalmol 1950; 43: 466-81.

13 Weymouth FW. In: Hirsch MJ, Wick RE, eds. Vision of the ageing patient. London: Hamond and $\mathrm{Co}, 1961: 37-62$.

14 Department of Health. Assessing the effects of health technologies. London: Department of Health, 1992.

15 Rizzo JF, Feke G, Gager D, Ogasawara H, Weiter J. Optic nerve head blood speed as a function of age in normal human subjects. Invest Ophthalmol Vis Sci 1991; 32: 3263-72.

16 Saraux H, Offret H. Long term study of patients with iridectomy for angle closure glaucoma. Glaucoma 1979; 1: 149-51.

17 Krupin T, Mitchell KB, Johnson MF, Becker B. The long term effects of iridectomy for primary acute angle closure. Am 7 Ophthalmol 1978; 86. 506-9.

18 Johnstone MA, Grant WM. Pressure dependent changes in structures of the aqueous outflow system of human and monkey eyes. Am $\mathcal{F}$ Ophthalmol 1973; 75: 365-82.

19 Fleck BW, Dhillon B, Khanna V, Fairley E, McGlynn C. A randomised, prospective comparison of ND:YAG laser iridotomy and operative peripheral iridectomy in fellow eyes. Eye 1991; 5: 315-21.

20 Gifford $\mathrm{H}$. Peripheral iridotomy (Curran) in the treatment of glaucoma. Am f Ophthalmol 1921; 4: 889-94.

21 Gray RH, Hoare Nairne J, Ayliffe WHR. Efficacy of Nd-YAG laser iridotomies in acute angle closure glaucoma. $\mathrm{Br} f$ Ophthalmol 1989; 73: 182-5.

22 Chandler PA, Grant MW. Lectures on glaucoma. Philadelphia: Lea and Febiger, 1965. 